\title{
Operating Experience with High Beam Currents and Transient Beam Loading in the SLC Damping Rings*
}

\author{
M. G. Minty, R. Akre, P. Krejcik, R. H. Siemann \\ Stanford Linear Accelerator Center, Stanford University, Stanford, CA 94309 USA
}

During the 1994 SLC run the nominal operating intensity in the damping rings was raised from $3.5 \times 10^{10}$ to greater than $4 \times 10^{10}$ particles per bunch (ppb). Stricter regulation of $\mathrm{rf}$ system parameters was required to maintain stability of the If system and particle beam. Improvements were made in the feedback loops which control the cavity amplitude and loading angles. Compensation for beam loading was also required to prevent klystron saturation during repetition rate changes. To minimize the effects of transient loading on the if system; the gain of the direct if feedback loop and the loading angles were optimized.

\section{INTRODUCTION}

Modifications to the SLC damping ring if systems have been required as the beam intensities and beam environment change. During the 1992 run, beam intensities were limited to $3 \times 10^{10} \mathrm{ppb}$ by the microwave instability. ${ }^{1}$ In 1993 this instability was overcome using an If voluage ramp with direct if feedback, ${ }^{2}$ and the beam current was increased to $3.5 \times 10^{10} \mathrm{ppb}^{3}$ Prior to the 1994 run, low impedance vacuum chambers were installed to reduce the impedance of the damping rings. ${ }^{4}$ By reducing the effects of the microwave instability, the beam current could be increased. Transient loading on the if system, however, occasionally caused loss of regulation of the cavity voltage. 5 As a result, both the bunch length and the beam phase changed at extraction. Such changes caused unacceptable wakefieldinduced emittance growth and beam jitter in the linear collider. Stricter tolerances on cavity voltage regulation were therefore required at higher operating currents. With modifications to the feedback loops, beam currents were increased to over $4.0 \times 10^{10} \mathrm{ppb}$. Some operating parameters for the SLC damping rings are given in Table I.

Table I. Cavity, Beam, And Klystron Properties In The SLC Damping Rings For The Past Three Runs

\begin{tabular}{|l|l|l|l|l|}
\hline $\begin{array}{l}\text { Symbol } \\
\mathrm{V}_{\mathrm{c}} \\
\mathrm{MV})\end{array}$ & \multicolumn{1}{|c|}{ Variable } & 1992 & 1993 & 1994 \\
\hline $\mathrm{I}_{\mathrm{b}}(\mathrm{A})$ & $\begin{array}{l}\text { If Beam Current } \\
=2 \times \mathrm{dc} \text { Current }\end{array}$ & 0.16 & 0.19 & 0.22 \\
\hline $\begin{array}{l}\mathrm{N} \\
\left(\times 10^{19}\right.\end{array}$ & Particles per Bunch & 3 & 3.5 & $\begin{array}{l}4.0- \\
4.5\end{array}$ \\
\hline $\begin{array}{l}\mathrm{P}_{\max } \\
(\mathrm{kW})\end{array}$ & $\begin{array}{l}\text { Max. Klystron Output } \\
\text { Power }\end{array}$ & 50 & 60 & 50 \\
\hline$\phi_{z}(\mathrm{deg})$ & Tuning Angle & -45 & -43 & -49 \\
\hline$\phi_{l}(\mathrm{deg})$ & Loading Angle & 0 & 0 & 10 \\
\hline
\end{tabular}

\section{FEEDBACK REGULATION}

A block diagram of the SLC damping ring if system is shown in Fig. 1. The cavity voltage is maintained at the desired value $V_{\text {des }}$ by the amplitude feedback loop. The beam phase is regulated to $\phi_{\text {des }}$ by the phase feedback loop. The phase offset $\phi_{\text {inj }}$ is the offset required to match the injected beam to the damping ring bucket. Likewise $\phi_{\text {des }}$ is adjusted to match the extracted beam to the accepting bucket of the linear accelerator. The direct if feedback loop, which was used previously to avoid the beam loading instability, 3 is currently used to minimize the effects of transient loading (see section IV). Not shown in Fig. 1 are the slow cavity uner loops which regulate the loading angle $\phi l$. The loading angle is the measured phase difference between the generator current and the cavity voltage which is different from the wning angle $\phi_{z}$ at high beam current.

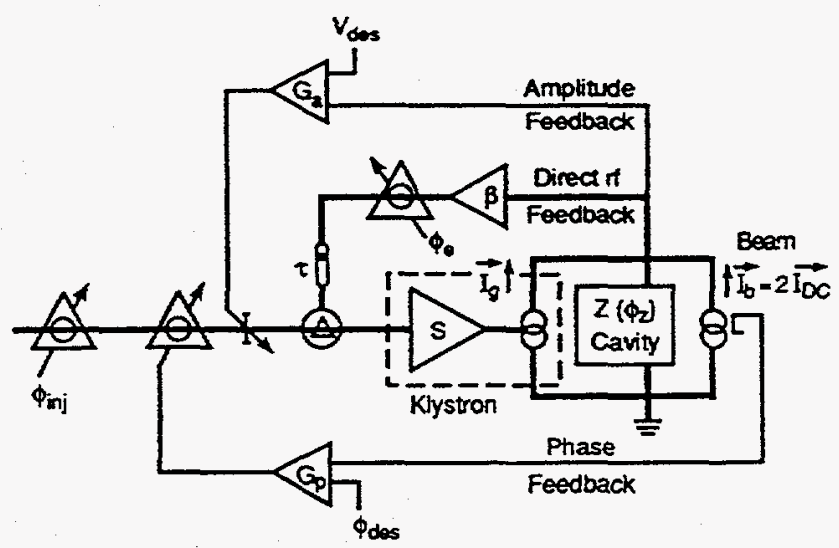

Figure 1. The SLC damping ring if system. Included are amplitude, beam phase, and direct if feedbacks. The thick lines indicate paths for phasors with both phase and amplitude.

\section{Amplitude Feedback Loop}

The open loop gain of the amplitude feedback loop contains a number of nonlinear elements including a nonlinear power limiter and a nonlinear klystron. This gain can therefore change depending upon the operating power of the klystron which in tum depends both on the beam current and the cavity voltage. Problems with cavity voltage regulation were observed when running either high beam currents or high cavity voltage. These were found to be due to a low open loop gain, which resulted in the closed loop gain of the loop becoming dependent on the open loop gain. When the open loop gain changed, regulation was affected as

* Work supported by the Department of Energy, contract DE-AC03-76SF00515. 
a result. The problem was corrected by increasing the open loop gain.

\section{Tuner Feedback Loops}

Until recently the cavity tuners were not carefully regulated. Difficulties arising from beam-related heating of the If cavities however have necessitated careful control. The tuners, which regulate the phase between the generator and cavity voltages, are sampled and held once per cycle. Initially the tuner dead band was about $8^{\circ}$ which was limited by the noise level in the phase measurement. To improve the signal-to-noise ratio, a filter was added after the sample and hold module which allowed the dead band to be reduced to $1^{\circ}$. The speed of the tuners, motor-driven tuning plungers, has also been decreased to prevent oscillations. These modifications resulted in a greater degree of stability in the loading angle. Occasional problems related to loss of regulation, however, still persist upon recovery from an extended period without beam.
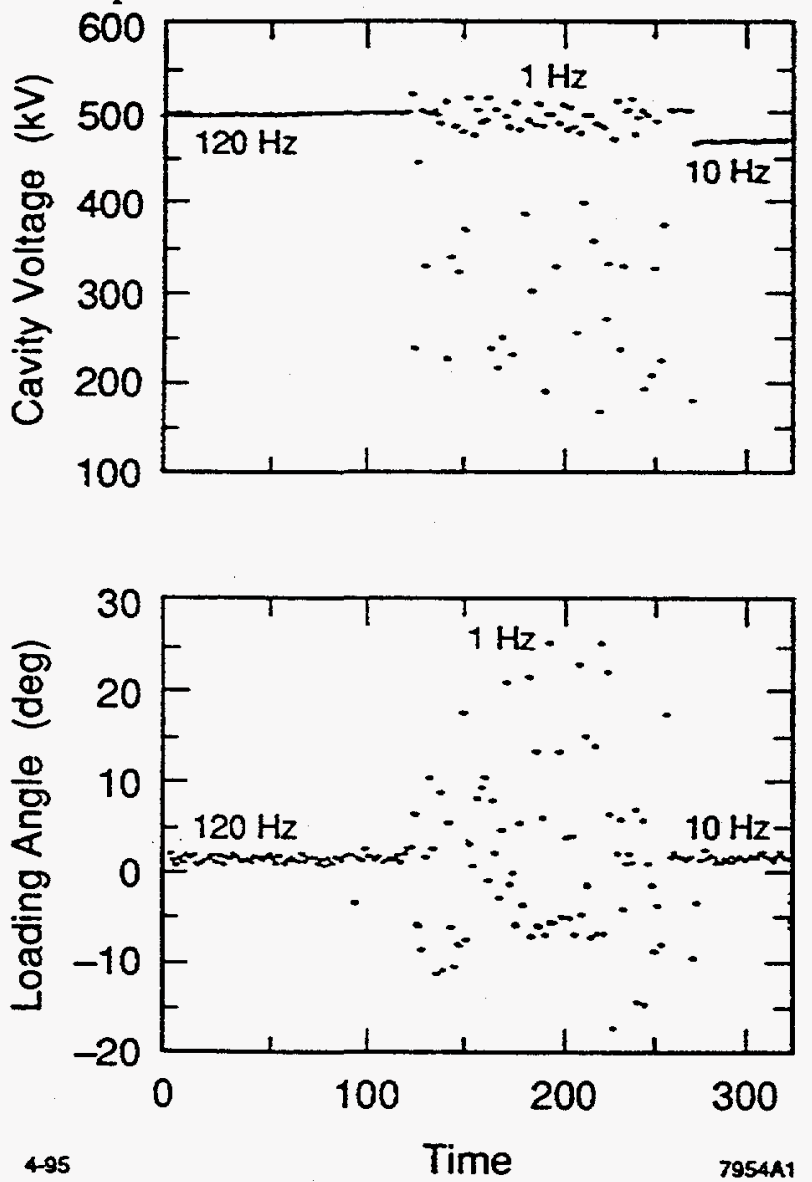

Figure 2. Measured cavity voltage and loading angle during rate limiting.

\section{COMPENSATION FOR REPETITION RATE CHANGES}

To avoid damage to accelerator components from beam heating, the repetition frequency is occasionally reduced from $120 \mathrm{~Hz}$ to $10 \mathrm{~Hz}$ or $1 \mathrm{~Hz}$. At low rate the slow tuner feedback loops could respond to changes in the loading angle. As shown in Fig. 2 the tuner positions and cavity voltage lost regulation under $1 \mathrm{~Hz}$ operation. In this example the loading angle was nominally regulated to $\phi_{l}=$ $0^{\circ}$ while the tuning angle, the phase between the voltage and the current, was $\phi_{2}=-45^{\circ}$. When the beam was extracted therefore, the tuners would move and the cavity would be unregulated at injection. To avoid this, a beam-presence condition was added which fixed the tuner positions in the absence of beam.

With direct if feedback, the long absence of beam due to rate limiting also caused problems. Because the instantaneous power requirements are higher with direct if feedback, a limiter just upstream of the klystron was added to prevent klystron saturation in the 1993 run. Initial high current experiments at the end of the 1993 rin showed that simple limiting was insufficient for maintaining stability during rate-limiting at even higher beam currents. Instead, an intermediate level voltage was summed with the reference input to the amplitude feedback loop ( $V_{\text {des }}$ in Fig. 1) during rate-limiting.

\section{MINIMIZATION OF TRANSIENT LOADING EFFECTS}

With the steady-state defined by operation with beam, the dominant transient loading effects are caused by injection and extraction of the beam. 5.6 Because direct if feedback effectively deQ's the cavity and therefore decreases the cavity fill time, this feedback proved useful in minimizing the effect of beam loading since the if system is rapidly able to compensate for the fast changes. Without direct if feedback and with high currents substantial beam losses resulted from the large cavity voltage oscillations induced by injection. Transients in the cavity voltage are shown in Fig. 3 with the direct if feedback loop off $(G=0 \mathrm{~dB})$ and on $(G=$ $20 \mathrm{~dB}$ ). Beam extraction is indicated by the initial discontinuity near $30 \mu \mathrm{s}$. The next discontinuity $13 \mu$ s later corresponds to beam injection. Without direct if feedback the voltage oscillated by about $400 \mathrm{kV}$ peak-to-peak. With $\mathrm{G}=20 \mathrm{~dB}$ the oscillations were reduced to $220 \mathrm{kV}$ peak-topeak. Numerical analysis results showing the effect that direct if feedback has in reducing these transient oscillations are presented in Ref. 5 .

Transient oscillations may be further reduced by ensuring that the beam is properly injected into the center of the if bucket. The beam phase at extraction is regulated by feedback to ensure proper injection into the linear accelerator. At extraction the if phase is reset to prepare for injection which is $13 \mu \mathrm{s}$ later. The phase at injection is a relative phase offset between the damping ring and injection linac. Typically this phase offset ( $\phi_{i n j}$ in Fig. 1 ) is checked periodically and adjusted by minimizing the amplitude of the transient oscillations while viewing the if waveform on an oscilloscope. 


\section{DISCLAIMER}

This report was prepared as an account of work sponsored by an agency of the United States Government. Neither the United States Government nor any agency thereof, nor any of their employees, makes any warranty, express or implied, or assumes any legal liability or responsibility for the accuracy, completeness, or usefulness of any information, apparatus, product, or process disclosed, or represents that its use would not infringe privately owned rights. Reference herein to any specific commercial product, process, or service by trade name, trademark, manufacturer, or otherwise does not necessarily constitute or imply its endorsement, recommendation, or favoring by the United States Government or any agency thereof. The views and opinions of authors expressed herein do not necessarily state or reflect those of the United States Government or any agency thereof. 


\section{DISCLAIMER}

Portions of this document may be illegible in electronic image products. Images are produced from the best available original document. 


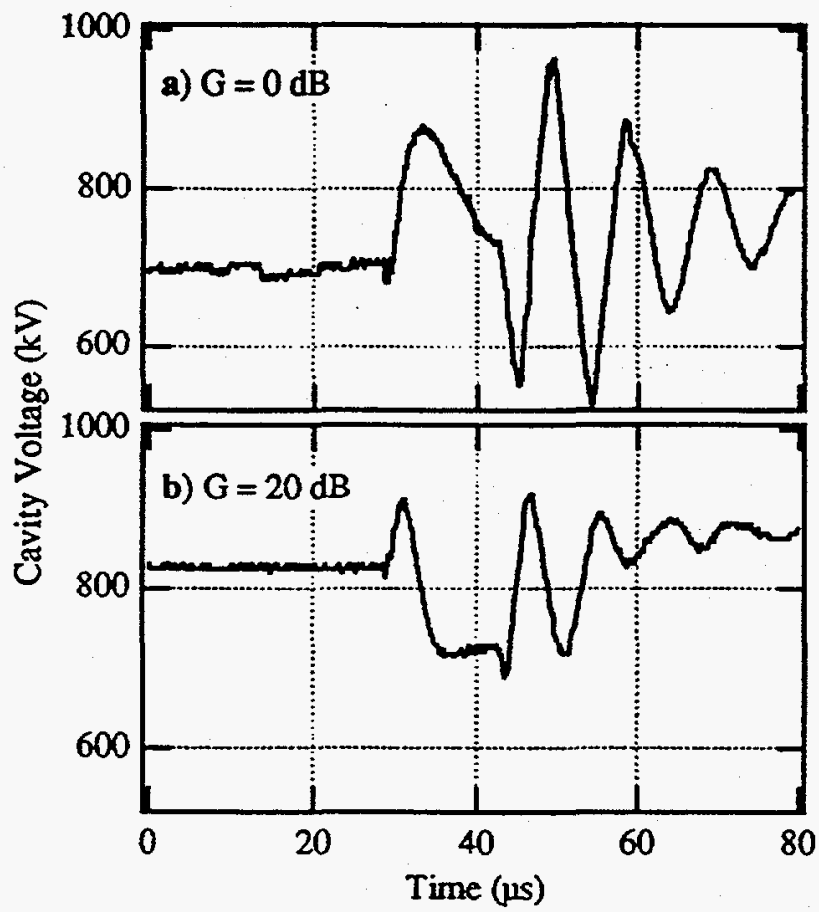

Figure 3. Cavity voltage with two different direct if feedback gains. $\phi_{l}=0^{\circ} ; \phi_{\text {inj }}=45^{\circ}$.

Finally, transient oscillations were minimized by intentional detuning of the loading angle. As shown in Fig. 3 a large voltage error on the accelerating cavity resulted when the direct if feedback loop was on. By adjusting the tuner feedback loop set point to positive loading angle under nominal conditions with beam, this problem was alleviated. Transient oscillations in the cavity voltage are plotted as a function of time with direct if feedback on at different loading angles in Fig. 4. As the loading angle increased, the amplitude of the transients decreased as expected. ${ }^{5}$ In the first two plots, when the beam was extracted the cavity voltage was not maintained. As a result, the voltage at injection was out of regulation. At $\phi_{l}=+10^{\circ}$ the voltage was regulated when the beam was absent. At $\phi_{l}=23^{\circ}$ the cavity voltage was already out of regulation before the beam was extracted. At extraction the cavity voltage increased towards its regulated value

\section{SUMMARY}

Modifications to the $\mathrm{rf}$ systems in the SLC damping rings were required to overcome instabilities related to heavy beam loading. The if system was tuned to minimize transient beam loading effects. For future running at higher beam currents, we will try to ensure that the klystron is capable of operating at higher power levels (as in 1993). Modifications to the amplitude feedback hardware and logic are also being considered to provide better stability.

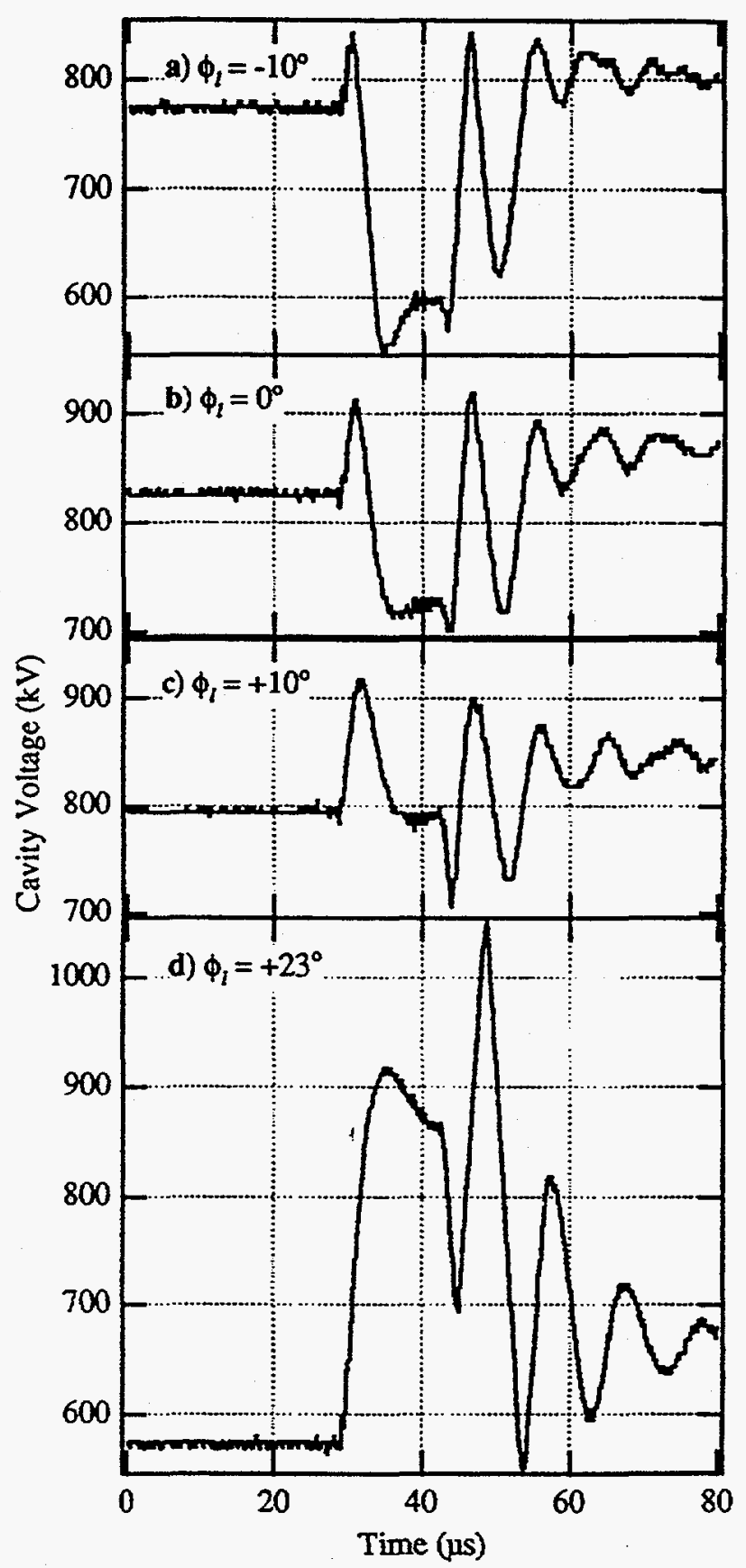

Figure 4. Cavity voltage as a function of time with $G=20$ $\mathrm{dB}$ and variable loading angle $\phi_{l} . \phi_{\text {inj }}=45^{\circ}$.

\section{REFERENCES}

1. P. Krejcik et al, Proc 1993 PAC, 3240 (1993).

2. F. Pederson, IEEE Tran, on Nucl. Sci, NS-32, 2138 (1985).

3. P. Krejcik et al, Proc 1993 PAC, 2370 (1993).

4. K. Bane et al, WAC17 1995 PAC.

5. M. Minty \& R.H. Siemann, TPA09 1995 PAC.

6. M. Minty \& R.H. Siemann, RAP10 1995 PAC. 